\title{
Effect of Advanced Platelet-rich Fibrin on Wound Healing after Third Molar Extraction: A Split-mouth Randomized Double-blind Study
}

\author{
Talal M Zahid ${ }^{1}$, Mohammed Nadershah ${ }^{2}$
}

\begin{abstract}
Aim: To evaluate the potential of advanced platelet-rich fibrin (A-PRF) as a regenerative biomaterial for bone regeneration and postoperative sequelae after impacted third molar extractions.

Materials and methods: This was a split-mouth, randomized, double-blind clinical trial. A total of 10 female patients in King Abdulaziz University Dental Hospital with bilateral impacted third molars were recruited into the study. Surgical extractions were performed on both sides of the mandible. Randomization was done by a coin toss; A-PRF was placed on the one side while the other side did not receive any intervention. Each patient acted as their own control. Both the patients and the investigators were blinded about the A-PRF side. The outcome on periodontal regeneration was made measuring pocket depth (PD), gum recession (GR), and clinical attachment level (CAL) before and at 1- and 3-months postoperatively. Pain, swelling, and healing were assessed on the 7th postoperative day. $p$ value less than 0.05 was considered statistically significant.

Results: An estimated 10 patients completed the study. There were no significant differences in PD, CAL, and GR between the two groups at any time point, although the data obtained were slightly favoring the A-PRF. However, a statistically significant reduction in pain and swelling was observed in the A-PRF group compared to the controls $(p<0.05)$.

Conclusion: The findings of this study demonstrate A-PRF as a potential biomaterial for lessening the severity of pain and swelling after third molar surgery. Long-term trials with a larger sample size and more methodically sound assessment tools are needed to obtain more meaningful results on periodontal regeneration.

Clinical significance: Placement of A-PRF clot in the extraction socket could lessen postoperative pain and increase patient comfort after third molar extraction.

Trial registration: NCT03703479. Registered 8 October 2018

Keywords: Healing, Impacted third molar surgery, Pain, Platelet-rich fibrin, Regeneration, Swelling, Wound healing.

The Journal of Contemporary Dental Practice (2019): 10.5005/jp-journals-10024-2666
\end{abstract}

\section{INTRODUCTION}

Extraction of impacted third molars is one of the most common procedures that has routinely been performed in a typical dental practice. However, this procedure has been associated with several postoperative complications such as pain, swelling, bleeding, trismus, nerve injury, and dry socket.' In addition, alveolar defect distal to the second molar and general oral dysfunction are common sequela after surgical removal of an impacted third molar. ${ }^{2}$ Because surgical extraction of third molars often requires marked bone removal to expose the tooth, which may potentially jeopardize the alveolar ridge and periodontal health distal to second molars, preservation of the alveolar ridge is a mandatory step after the surgery. Hence, various bone substitutes (e.g. autograft, alloplast, and allograft) and biologics (e.g. growth factors, platelet-rich plasma) have been used to counter this side effect. ${ }^{3}$

Platelet-rich fibrin (PRF) is a second-generation autologous platelet concentration that is obtained from the patient's own blood in a simple and cost-effective manner. ${ }^{4}$ It has been developed as a cheaper but more biocompatible and effective alternative over the previously introduced platelet-rich plasma (PRP) for bone and soft tissue regeneration. Compared to PRP, PRF is less soluble after application, requires minimal handling of biochemical blood, and provides a more sustained release of platelet cytokines and growth factors. ${ }^{5}$ PRF has been shown to release a number of
${ }^{1}$ Periodontology Department, Faculty of Dentistry, King Abdulaziz University, Jeddah, Kingdom of Saudi Arabia

${ }^{2}$ Oral and Maxillofacial Surgery Department, Faculty of Dentistry, King Abdulaziz University, Jeddah, Kingdom of Saudi Arabia

Corresponding Author: Talal M Zahid, Periodontology Department, Faculty of Dentistry, King Abdulaziz University Jeddah, Kingdom of Saudi Arabia, Phone: +966 554667998, e-mail:Tzahid@kau.edu.sa

How to cite this article: Zahid TM, Nadershah M. Effect of Advanced Platelet-rich Fibrin on Wound Healing after Third Molar Extraction: A Split-mouth Randomized Double-blind Study. J Contemp Dent Pract 2019;20(10):1164-1170.

Source of support: Nil

Conflict of interest: None

key growth factors, including transforming growth factor $\beta-1$ (TGF $\beta-1$ ), platelet-derived growth factor $A B$ (PDGF-AB), and vascular endothelial growth factor (VEGF). It also releases a homotrimeric, multifunctional glycoprotein (thrombospondin-1, TSP-1), and several pro-inflammatory cytokines such as tumor necrosis factor-a (TNF-a), interleukin 6 (IL-6), and interleukin-1 $\beta$ (IL-1 $\beta){ }^{6}$

Recently, Choukroun developed a modified form of PRF, known as A-PRF. ${ }^{7}$ A-PRF clot is softer compared to PRF and contains a relatively higher number of autologous cells such as neutrophils and macrophages. ${ }^{8}$ A recent in vitro study by Kobayashi et al. showed

(c) The Author(s). 2019 Open Access This article is distributed under the terms of the Creative Commons Attribution 4.0 International License (https://creativecommons. org/licenses/by-nc/4.0/), which permits unrestricted use, distribution, and non-commercial reproduction in any medium, provided you give appropriate credit to the original author(s) and the source, provide a link to the Creative Commons license, and indicate if changes were made. The Creative Commons Public Domain Dedication waiver (http://creativecommons.org/publicdomain/zero/1.0/) applies to the data made available in this article, unless otherwise stated. 
that A-PRF releases a significantly greater number of growth factors than PRF. ${ }^{9}$ More recently, in a randomized trial, Clark et al. demonstrated A-PRF as a potential biomaterial for alveolar ridge preservation. ${ }^{10}$ Hence, this new formulation has been thought to be a more potent biomaterial for bone and soft tissue regeneration than the traditional PRF. However, evidence in support of the A-PRF's effectiveness in periodontal wound healing is still limited, and there is a need for standardized randomized controlled clinical trials to assess the effect of A-PRF following surgical extraction of third molars. Therefore, the aim of the present study is to evaluate the effect of A-PRF on wound healing characteristics of the third molar socket after extraction and patient comfort.

\section{Materials and Methods}

\section{Study Design}

This was a split-mouth, randomized, double-blind clinical trial. The ethical approval for this study (Proposal ID 085-10-17) was obtained from the institutional ethics committee at the Faculty of Dentistry, King Abdulaziz University in Jeddah, Kingdom of Saudi Arabia. The study was conducted and reported in accordance with guidelines published by the CONSORT group and the World Medical Association's Helsinki Declaration of 1975, as revised in 2013. This study is registered at ClinicalTrials.gov with clinical trial registration number NCT03703479.

The study was conducted in King Abdulaziz University Dental Hospital, and the sample size calculation was done based on previous similar studies done by Uyanik et al. and Yelamali et al. ${ }^{11,12} 40$ patients were screened, and after preoperative and radiographic evaluation, 10 female patients with a mirror-imaged vertical or mesioangular bilateral impacted mandibular third molars were included in the study (Fig. 1). Written informed consent was obtained from each patient before recruitment. All recruited patients acted as their own control. Inclusion criteria included: (1) healthy patients with no systemic diseases, (2) age $\geq 18$ years, and (3) non-smoker. Exclusion criteria were as follows: (1) missing second molars; (2) decayed second molar that is indicated for extraction (un-restorable and remaining roots); (3) patients under immunosuppressant or with acute infection; (4) inability or failure to attend follow-up appointments.

\section{Surgical Procedure}

All patients underwent bilateral extraction of impacted lower third molars, which were of the same level of removal difficulty. The teeth

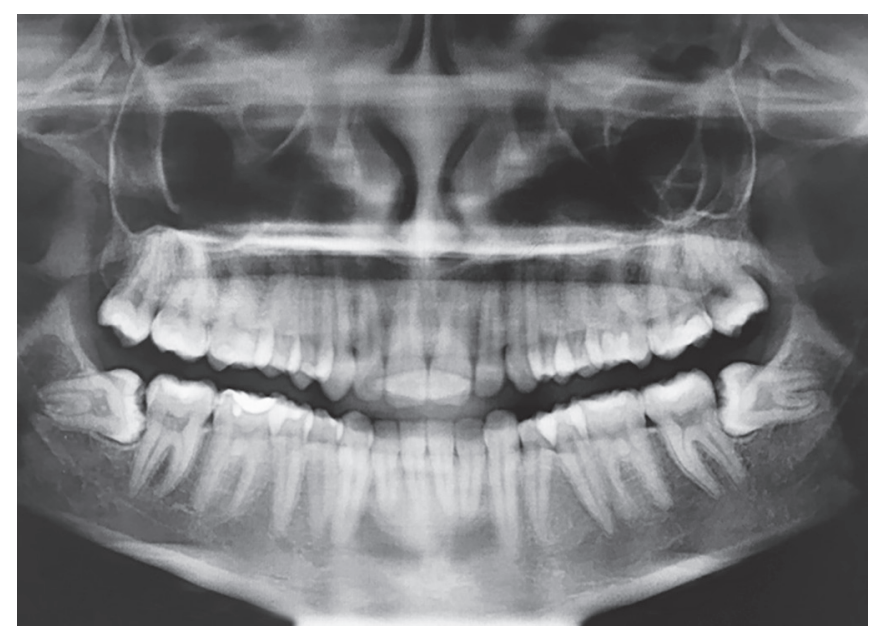

Fig. 1: Preoperative radiographic evaluation were surgically removed in a single appointment. Two sites in the second molar were selected as experimental units: (1) distobuccal (DB) site and (2) distolingual (DL) site. These two sites were chosen owing to their close proximity to the extracted tooth. Each one of the extraction sites received the biomaterial (A-PRF) while the other acted as a control. A coin toss was performed by an intern to randomly choose which side would receive the A-PRF. Both the patients and the investigators were blinded about the A-PRF side.

A maxillofacial surgeon carried out all surgical procedures following a standard operating technique. Strict aseptic precautions were undertaken prior to and during the surgery. For local anesthesia, an inferior alveolar nerve block was used, and the long buccal infiltration was administered using scandonest $2 \%$ containing 1:200,000 epinephrine. Envelope flap with distal extension was performed. A full-thickness mucoperiosteal flap was raised, and the tooth was extracted using elevators. The socket was then thoroughly irrigated with sterile $0.9 \%$ saline. To obtain A-PRF, 2 tubes ( $10 \mathrm{~mL}$ each) of venous blood was drawn. The tubes used were sterile vacuum plain tubes for $\mathrm{A}-\mathrm{PRF}^{\mathrm{TM}}+$ and did not contain any additive or anticoagulant. They were then placed in the centrifugation machine (DUO from the PROCESS FOR PRF Company) (Fig. 2) for 13 minutes at $1300 \mathrm{rpm}$. The end products (A-PRFs) were then placed in the PRF Box ${ }^{\circledR}$ to preserve the membrane and provide constant thickness (Fig. 3). After the A-PRF was placed in the socket (Fig. 4), primary closure of both extraction cavities was performed using 3.0 chromic gut sutures (Fig. 5).

Postoperatively, all patients were treated with an oral antibiotic (amoxicillin 500 mg, 8 hourly for 3 days) and a non-steroidal antiinflammatory medication (ibuprofen $600 \mathrm{mg}, 8$ hourly for 2 days). Postoperative oral hygiene instructions were also given to all patients, and a mouthwash $(0.12 \%$ chlorhexidine thrice daily) was prescribed for 7 days. Sutures were removed on the 7 th day.

\section{Outcome Assessment}

Outcomes were assessed using several measures, including pocket depth (PD), clinical attachment level (CAL), gum recession (GR), and visual scoring of pain, swelling, and healing. PD, GR, and CAL distal to the mandibular second molar were measured at $B D$ and $D L$ sites by a single examiner. Three time points were used to assess them: (t1) pre-surgery, (t2) 1-month post extraction, and (t3) three months' post extraction. A periodontal probe was used to measure the PD. GR was expressed using negative values to indicate whether the gum tissue recessed from its original position. A high negative

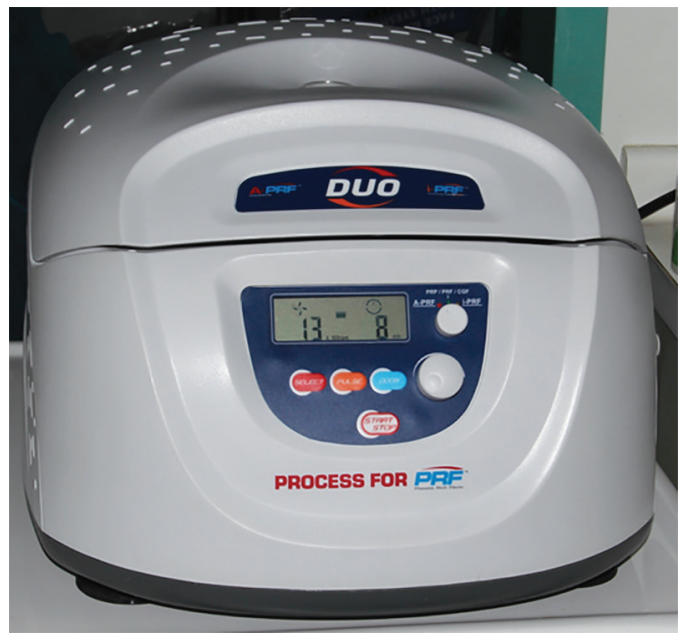

Fig. 2: PRF DUO from the PROCESS FOR PRF Company 


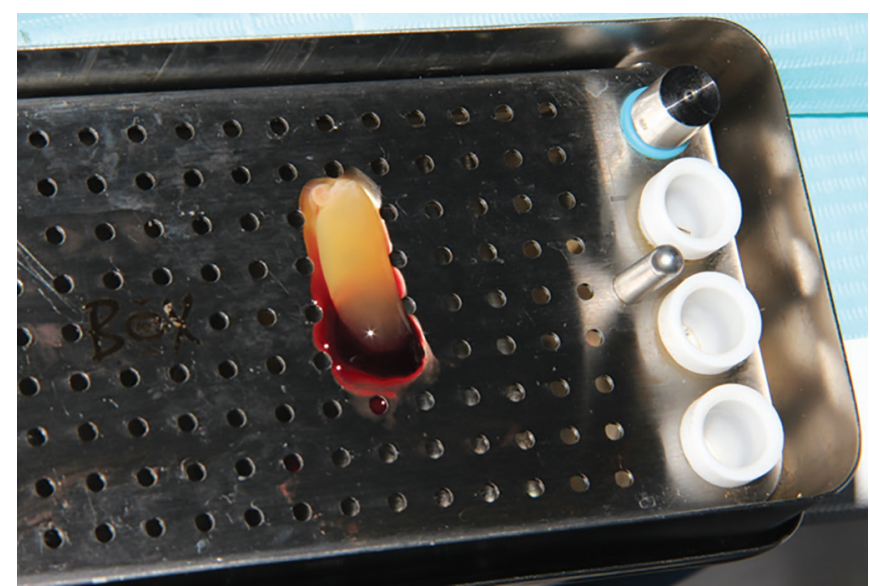

Fig. 3: PFR clot in PRF Box ${ }^{\circledast}$

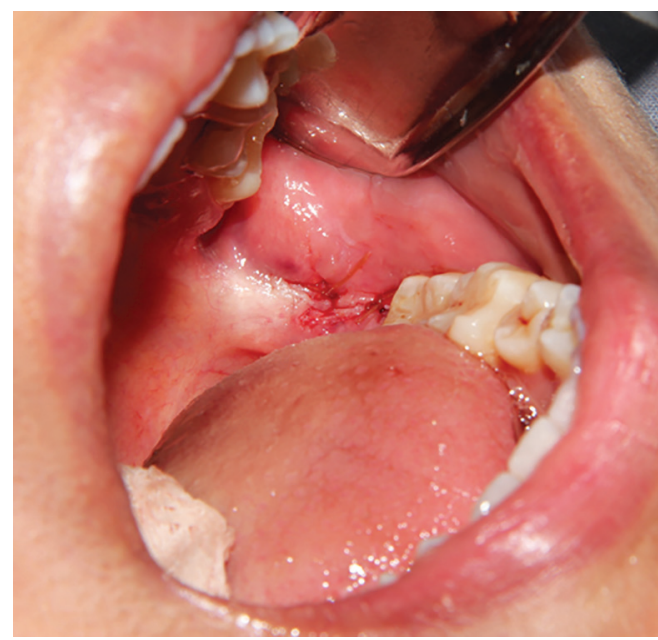

Fig. 5: Flap sutured covering the PRF membrane

Table 1: Measurement of pain, swelling, and healing

\begin{tabular}{lll}
\hline Scale & Score & Variables \\
\hline Pain (VAS) & 0 & None \\
& $0.1-3.0 \mathrm{~cm}$ & Mild \\
& $3.1-6.0 \mathrm{~cm}$ & Moderate \\
Swelling & $6.1-10 \mathrm{~cm}$ & Severe \\
& 0 & None \\
& 1 & Mild \\
Healing & 2 & Moderate \\
& 3 & Severe \\
& 0 & Healed \\
& 1 & Inflamed \\
& 2 & Collapse \\
& 3 & Recession \\
\hline
\end{tabular}

value indicated a higher than normal gum position, while a near positive value meant the opposite. Pain, swelling, and healing were recorded using visual scores on the 7th, 15th, and 90th days (Table 1). Patients were asked about the level of pain experienced using a visual analog scale (VAS). Visual scores on facial swelling and healing progress were based on clinical observation.

\section{Data Analysis}

Statistical analysis was performed using R Studio software (version 3.4, RStudio Inc., Boston, MA, USA). Continuous variables such as

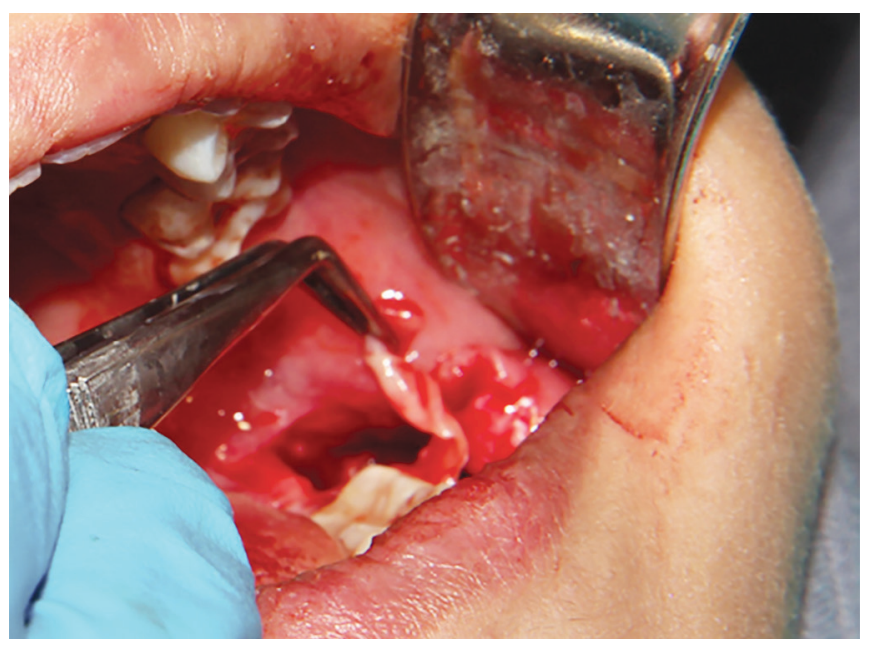

Fig. 4: PRF placement in the extraction socket

PD, GR, and CAL outcomes were expressed as mean $(\bar{x}) \pm$ standard deviation (SD). Categorical data such as visual scores of swelling and healing were summarized as counts and percentages. VAS score was expressed using median/IQR. The difference in confidence interval was also calculated for VAS. A mixed ANOVA was used to assess the association between the intervention (vs control) and the outcome of interest at various time points. Site, time, and treatment were included as fixed effects, while subjects were treated as random variables considering the split-mouth design used. The significance of the fixed effects ( $p$ values) was assessed using the Kenwood-Roger (KR) approximation. Pain, swelling, and healing scores were compared using paired Wilcoxon signed-rank test. Pairwise $t$ tests with Tukey's HSD correction was performed as a post hoc test. Two-tailed hypothesis testing was performed using a significance level of 0.05 .

\section{Results}

An estimated 10 female patients were included in the study. The mean age of these participants was 24 years. Each patient acted as their own control. Teeth were removed from both the left and right side of the mandible, and two sites, DB and DL, were chosen from each tooth for comparison. Preoperative mean values of PD, $G R$, and CAL in the A-PRF and control groups were comparable. There was also no statistical difference between the sites of two groups (Table 2).

A statistically significant decrease in PD was observed in both groups at 1 - and 3-months postoperatively compared to preoperative baseline (Table 3 ). The mean value of PD was slightly lower in the A-PRF group ( $p=0.002)$ than control $(p=0.014)$ at 1-month post-surgery. No significant difference was found between the 1- and 3-months postoperative PD values for both groups. Similar results were obtained when the analysis was performed separately for DB and DL sites (Table 2). The mixed ANOVA analysis revealed that the decrease in PD was significantly associated with time $(p<0.001)$, but not with the site or treatment group (Table 4).

GR decreased significantly in the intervention $(p<0.001)$ and control ( $p=0.01$ ) groups at 1 -month post-surgery than preoperative baseline (Table 3). There was a statistically significant difference between the 1- and 3-months postoperative GR values in both groups. The mean decrease in GR at 1- and 3-months postoperatively was more evident in the A-PRF-treated DB sites 
Effect of A-PRF on Wound Healing after Third Molar Extraction

Table 2: Sitewise comparison of PD, GR and CAL in A-PRF and control groups preoperatively and 1 and 3 months postoperatively

\begin{tabular}{|c|c|c|c|c|c|c|c|}
\hline \multirow[b]{3}{*}{ Site } & \multirow[b]{3}{*}{ Time } & \multicolumn{2}{|c|}{$P D$} & \multicolumn{2}{|c|}{$G R$} & \multicolumn{2}{|c|}{$C A L$} \\
\hline & & Control & $A-P R F$ & Control & $A-P R F$ & Control & $A-P R F$ \\
\hline & & $\bar{x}(S D)$ & $\bar{x}(S D)$ & $\bar{x}(S D)$ & $\bar{x}(S D)$ & $\bar{x}(S D)$ & $\bar{x}(S D)$ \\
\hline \multirow[t]{3}{*}{ DB } & $\mathrm{t} 1$ & $4.6(0.97)$ & $4.4(1.35)$ & $-2.6(0.84)$ & $-2.4(0.84)$ & $2(0.94)$ & $1.8(1.23)$ \\
\hline & $\mathrm{t} 2$ & $3.3(1.34)$ & $3.2(0.92)$ & $-1.2(2.3)$ & $-0.1(1.67)$ & $2.1(1.19)$ & $3.1(1.37)$ \\
\hline & t3 & $3.7(2.2)$ & $3.2(0.92)$ & $-2.1(2.23)$ & $-1.2(2.3)$ & $1.6(1.9)$ & $2(1.83)$ \\
\hline \multirow[t]{3}{*}{ DL } & $\mathrm{t} 1$ & $4.1(0.74)$ & $4.3(0.95)$ & $-2.8(0.92)$ & $-2.6(0.84)$ & $1.4(0.84)$ & $1.5(0.97)$ \\
\hline & $\mathrm{t} 2$ & $3.6(1.74)$ & $3.3(1.16)$ & $-2.9(1)$ & $-2.9(1)$ & 0.7 (1.06) & $0.4(0.97)$ \\
\hline & t3 & $3.4(0.97)$ & $3.3(0.48)$ & $-3(1.94)$ & $-3.1(0.74)$ & $0.4(1.2)$ & $0.2(0.42)$ \\
\hline
\end{tabular}

$\bar{x}$, mean; SD, standard deviation; PD, pocket depth; GR, gum recession; CAL, clinical attachment level; DB, distobuccal; DL, distolingual; t1, presurgery; t2, 1-month postsurgery; $\mathrm{t} 3$, 3-months postsurgery

*Statistically significant $(p<0.05)$

Table 3: Pre- and postoperative comparison of PD, GR and CAL in A-PRF and control groups

\begin{tabular}{|c|c|c|c|c|c|c|c|}
\hline \multirow[b]{2}{*}{ Time } & \multirow[b]{2}{*}{ Groups } & \multicolumn{2}{|c|}{$P D$} & \multicolumn{2}{|c|}{$G R$} & \multicolumn{2}{|c|}{$C A L$} \\
\hline & & Mean difference & $p$ value & Mean difference & pvalue & Mean difference & $p$ value \\
\hline $\mathrm{t} 1-\mathrm{t} 2$ & Control $(n=10)$ & 2.855 & $0.014^{*}$ & -3.11 & $0.01 *$ & 0.83 & 0.681 \\
\hline t1-t3 & & 3.352 & $0.003^{*}$ & -0.22 & 0.93 & 1.95 & 0.13 \\
\hline t2-t3 & & 0.539 & 0.852 & 2.77 & $0.02^{*}$ & 1.11 & 0.507 \\
\hline t1-t2 & A-PRF $(n=10)$ & 3.49 & $0.002^{*}$ & -5.11 & $<0.001^{*}$ & -0.28 & 0.958 \\
\hline $\mathrm{t} 1-\mathrm{t} 3$ & & 3.49 & $0.002^{*}$ & -0.73 & 0.93 & 1.53 & 0.28 \\
\hline t2-t3 & & 0 & 1 & 3.98 & $<0.001^{*}$ & 1.81 & 0.171 \\
\hline
\end{tabular}

$\mathrm{PD}$, pocket depth; GR, gum recession; CAL, clinical attachment level; $\mathrm{t} 1$, presurgery; $\mathrm{t} 2$, 1-month postsurgery; $\mathrm{t}$, 3-months postsurgery

*Statistically significant $(p<0.05)$

Table 4: Mixed ANOVA results

\begin{tabular}{|c|c|c|c|c|c|c|c|c|c|}
\hline \multirow[b]{2}{*}{ Effect } & \multicolumn{3}{|c|}{$P D$} & \multicolumn{3}{|c|}{$G R$} & \multicolumn{3}{|c|}{$C A L$} \\
\hline & $d f$ & $F$ & $p$ value & $d f$ & $F$ & $p$ value & $d f$ & $F$ & $p$ value \\
\hline Site & $1,98.08$ & 0.02 & 0.9 & 1,9 & 15.19 & $0.004^{*}$ & 1,99 & 41.44 & $<0.0001^{*}$ \\
\hline Time & $2,98.08$ & 14.58 & $<0.001^{*}$ & 2,69 & 4.96 & $0.01^{*}$ & 2,99 & 3.50 & $0.03^{*}$ \\
\hline Treatment & $1,98.08$ & 0.17 & 0.68 & 1,9 & 2.32 & 0.16 & 1,99 & 0.41 & 0.52 \\
\hline Site : time & $2,98.08$ & 0.79 & 0.46 & 2,69 & 7.35 & $<0.001^{*}$ & 2,99 & 5.14 & $0.008^{*}$ \\
\hline Site : treatment & $1,98.08$ & 0 & 0.96 & $1,8.95$ & 1.79 & 0.21 & 1,99 & 1.66 & 0.2 \\
\hline Time : treatment & $2,98.08$ & 0.12 & 0.89 & 2,70 & 0.21 & 0.81 & 2,99 & 0.32 & 0.73 \\
\hline Site : time:treatment & $2,98.08$ & 0.28 & 0.76 & 2,70 & 0.64 & 0.53 & 2,99 & 1.25 & 0.29 \\
\hline
\end{tabular}

df, difference; $F$, factor; $P D$, pocket depth; GR, gum recession; $C A L$, clinical attachment level

* Statistically significant $(p<0.05)$

$(-0.1 \pm 1.67 \mathrm{~mm}$ and $-1.2 \pm 2.3 \mathrm{~mm}$, respectively) compared to nontreated DB sites $(-1.2 \pm 2.3 \mathrm{~mm}$ and $-2.1 \pm 2.23 \mathrm{~mm}$, respectively). At the DL sites, the change in gum recession across time was slight in both groups (Table 2). The mixed ANOVA analysis indicated that there was a statistically significant interaction between time and site $(F=7.35, p<0.001)$, which confirmed that the patterns observed in the DB and DL sites are indeed different (Table 4).

Pairwise comparison of pre- and post-operative values showed no statistically significant change in CAL in either of the two groups at any time point (Table 3). Sitewise comparison revealed an increase in mean CAL at 1-month postoperatively in the A-PRF-treated DB sites $(3.1 \pm 1.37 \mathrm{~mm})$ than control $(2.1 \pm 1.19 \mathrm{~mm})$. At the $\mathrm{DL}$ sites, a decrease in mean CAL was observed in both groups at 1- and 3-months postoperatively compared to pre-surgery baseline (Table 2). These differences across sites at various time points were confirmed in the mixed ANOVA analysis (Table 4), which found a statistically significant association between site and time $(F=5.14, p=0.008)$. Comparison of visual scores showed that pain $(p=0.01)$ and swelling $(p=0.04)$ on the 7 th postoperative day were significantly lower in the A-PRF group compared to the control group (Table 5). No statistically significant difference was found in healing scores between both groups.

\section{Discussion}

Wound healing after extraction of impacted third molars is a complex process that involves a highly coordinated interaction of 
Table 5: Pain, swelling, and healing scores in A-PRF and control groups

\begin{tabular}{lllll}
\hline \multicolumn{2}{l}{ Visual score } & Control $(n=10)$ & $A-P R F(n=10)$ & $p$ value \\
\hline Healing & 0 & $8(80 \%)$ & $8(80 \%)$ & 0.58 \\
& 1 & $2(20 \%)$ & $0(0 \%)$ & \\
& 2 & $0(0 \%)$ & $1(10 \%)$ & \\
Swelling & 3 & $0(0 \%)$ & $1(10 \%)$ & \\
& 0 & $2(20 \%)$ & $5(50 \%)$ & $0.04^{*}$ \\
& 1 & $5(50 \%)$ & $4(40 \%)$ & \\
& 2 & $2(20 \%)$ & $1(10 \%)$ & \\
& 3 & $1(10 \%)$ & $0(0 \%)$ & \\
Pain (VAS) & $5[4.25-6.75]$ & $2.5[2-4.75]$ & $0.01^{*}$ \\
\hline
\end{tabular}

Swelling and healing scores were summarized as counts/percentages. VAS score was summarized using median/IQR

*Statistically significant $(p<0.05)$

cellular, molecular, biochemical, and physiological mechanisms. Various therapeutic measures have been taken to minimize postoperative complications and preserve the distal root of the second molar. ${ }^{13}$ The application of PRF after surgical extraction of impacted third molars has been shown to be a valid approach to accelerate wound healing and minimize postoperative complications. ${ }^{5}$ In comparison to PRP, patients treated with PRF have demonstrated a significant reduction in PD and superior healing of soft tissue. ${ }^{12,14}$ Moreover, a majority of systematic reviews, animal experiments, and clinical trials published to date suggested PRF as an effective biomaterial to accelerate bone healing, stimulate osseous and epithelial tissue regeneration, and reduce postoperative pain, swelling, and trismus. ${ }^{5,15-18}$ However, contrary results have also been reported. ${ }^{19-22}$

The objective of this study was to test the potential of A-PRF, an advanced form of PRF, as a regenerative biomaterial to enhance bone regeneration and accelerate wound healing. Although A-PRF is known to contain more growth factors and autologous cells than $\mathrm{PRF}^{9}{ }^{9}$ to date, no study evaluated its effect on wound healing. In fact, so far only a small number of studies has been conducted to determine the true clinical significance of A-PRF. This study is the first randomized controlled trial that evaluates the effectiveness of A-PRF as a potential biomaterial for socket healing of the third molar.

In the present study, PD recorded postoperatively at 1 and 3 months showed a statistically significant reduction than baseline for both A-PRF and control groups. Although there was no significant difference between the postoperative PD values of both groups, comparison of two sites at 1- and 3-months postoperatively indicated slightly better results in the A-PRF group than in the control group. These findings are comparable with the results of other PRP and PRF studies in the literature. ${ }^{21,23-25}$ However, some studies have reported more improved results compared to our findings. Sammartino et al. reported a statistically significant reduction in PD at 12 weeks in the PRP group compared to the controls. ${ }^{26}$ Similar findings were again reported in another study by Sammartino et al. although the comparison made in this study was between PRP alone and PRP with a resorbable collagen membrane. ${ }^{27}$ Some studies have also reported a faster decrease of PD for the case group compared to the non-treated group. Kumar et al. observed a statistically significant decrease in PD at 1 month postoperatively for the case group, but not in the control group, which indicated a faster periodontal healing in the PRF treated group than the control. ${ }^{24}$
The effect of PRF on GR and CAL has been studied extensively in the literature. While some studies have positively supported the use of PRF for solving gingival recessions of Miller class I or II and suggested that there could be an additional gain in CAL, ${ }^{23,28-30}$ others reported no improvement in the root coverage or CAL with PRF alone or in combination with a coronally advanced flap. ${ }^{31,32}$ Supporting the latter studies, a recent systematic meta-analysis of seven clinical trials by Moraschini and Barboza also suggested that in comparison to other biomaterials, PRF did not show any significant improvement in terms of root coverage, $C A L$, or keratinized mucosa width in the management of Miller Class I and II GRs. ${ }^{33}$ In the present study, there were no statistically significant differences in GR and CAL between A-PRF and control groups at any time point. These findings are consistent with the reported literature that suggested no added advantage in terms of recession coverage or gain in CAL with PRF.

It has been well established in the literature that the use of PRF is a valid method to minimize postoperative pain and swelling after surgical extraction of third molars. A majority of studies published to date reported observing a statistically significant decrease in pain and swelling on the first few postoperative days in the PRF group compared to the control. ${ }^{11,20,24,34}$ In addition, a recent meta-analysis by $\mathrm{He}$ et al. has recommended the local application of PRF into the extraction sockets for relieving pain and swelling. ${ }^{5}$ However, some studies have also reported no significant differences in pain and swelling between the PRF and control groups. ${ }^{22,35,36}$ In our study, pain and swelling scores recorded on the 7th postoperative day were significantly lower in the A-PRF group than the control group, which are in accordance with the findings of Kumar et al., Uyanık et al., and He et al. ${ }^{5,11,24}$

This study had several limitations (including a small sample size, recruitment of only female subjects, and a short follow-up), which prevent generalizing the results to males. It would have been more appropriate to conduct this study with a larger sample that includes both male and female subjects. In addition, a follow-up of up to 6 months could have enabled more statistical power to detect differences in outcomes regarding the effect of A-PRF on bone regeneration.

\section{ConCLUSION}

The results of the present study suggest that the use of A-PRF can be a viable option for minimizing postoperative pain and swelling after surgical extraction of impacted third molars. However, A-PRF did not provide any added advantage in terms of probing depth reduction, recession coverage, and clinical attachment level gain compared to natural healing. Although the comparison of data at various time points slightly favored A-PRF over the non-treated control with respect to bone regeneration, the clinical relevance was non-significant. To obtain more meaningful outcomes, long-term randomized control studies are warranted with a larger sample and more methodically sound assessment tools.

\section{ACKnowledgments}

The authors thank Dr Lalyan esam bahha and Dr Yosra Faisal Alahmadi, who helped with data collection and data entry.

\section{Availability of Data and Materials}

The datasets used and/or analyzed during the current study are available from the corresponding author on reasonable request. 


\section{Authors' Contributions}

Talal M Zahid and Mohammed M Nadershah contributed to data collection, interpretation of data, designing the study and writing the manuscript. All authors have revised the manuscript and have approved the final manuscript prior to its submission.

\section{Ethics Approval and Consent to Participate}

This study adhered to CONSORT guidelines and was conducted in accordance with the World Medical Association Helsinki Declaration (Version 2013). The study protocol was approved by the Institutional Review Boards (IRBs) at King Abdulaziz University (proposal ID 085-10-17). All the participants were informed of the objectives, interventions, and possible risks and benefits of the study prior to enrollment, and written consent was obtained.

\section{References}

1. Deliverska EG, Petkova M. Complications after extraction of impacted third molars-literature review. Journal of IMAB-Annual Proceeding Scientific Papers 2016;22:1202-1211. DOI: 10.5272/ jimab.2016223.1202.

2. Stella PEM, Falci SGM, et al. Impact of mandibular third molar extraction in the second molar periodontal status: a prospective study. J Indian Soc Periodontol 2017;21(4):285-290. DOI: 10.4103/jisp. jisp_79_1710.4103/jisp.jisp_79_17.

3. Lee $C T$, Hum L, et al. The effect of regenerative periodontal therapy in preventing periodontal defects after the extraction of third molars: a systematic review and meta-analysis. J Am Dent Assoc 2016;147(9):709-719.e4. DOI: 10.1016/j.adaj.2016.03.005.

4. Choukroun J, Adda F, et al. PRF: an opportunity in perio-implantology (in French). Implantodontie 2000;42:55-62.

5. He Y, Chen J, et al. Local Application of Platelet-Rich Fibrin During Lower Third Molar Extraction Improves Treatment Outcomes. J Oral Maxillofac Surg 2017;75(12):2497-2506. DOI: 10.1016/ j.joms.2017.05.034.

6. Miron RJ, Zucchelli G, et al. Use of platelet-rich fibrin in regenerative dentistry: a systematic review. Clin Oral Investig 2017;21(6):1913-1927. DOI: 10.1007/s00784-017-2133-z.

7. Choukroun J. Advanced PRF \& i-PRF: Platelet Concentrates or Blood Concentrates? J Periodontal Med Clin Pract 2014;3.

8. Shahram Ghanaati PB, Orlowska A, et al. Advanced Platelet-Rich Fibrin: A New Concept for Cell-Based Tissue Engineering by Means of Inflammatory Cells. J Oral Implantol 2014;40(6):679-689. DOI: 10.1563/ aaid-joi-D-14-00138.

9. Kobayashi E, Fluckiger $\mathrm{L}$, et al. Comparative release of growth factors from PRP, PRF, and advanced-PRF. Clin Oral Investig 2016;20(9): 2353-2360. DOI: 10.1007/s00784-016-1719-1.

10. Clark D, Rajendran $Y$, et al. Advanced platelet-rich fibrin and freezedried bone allograft for ridge preservation: a randomized controlled clinical trial. J Periodontol 2018;89(4):379-387. DOI: 10.1002/JPER.170466.

11. Uyanık LO, Bilginaylar K, et al. Effects of platelet-rich fibrin and piezosurgery on impacted mandibular third molar surgery outcomes. Head Face Med 2015;11:25. DOI: 10.1186/s13005-015-0081-x.

12. Yelamali T, Saikrishna D. Role of platelet rich fibrin and platelet rich plasma in wound healing of extracted third molar sockets: a comparative study. J Maxillofac Oral Surg 2015;14(2):410-416. DOI: 10.1007/s12663-014-0638-4.

13. Marciani RD. Complications of third molar surgery and their management. Atlas Oral Maxillofac Surg Clin North Am 2012;20: 233-251. DOI: 10.1016/j.cxom.2012.06.003.

14. Doiphode AM, Hegde P, et al. Evaluation of the efficacy of platelet-rich plasma and platelet-rich fibrin in alveolar defects after removal of impacted bilateral mandibular third molars. J Int Soc Prev Community Dent 2016;6(1):S47-S52. DOI: 10.4103/2231-0762.181167.

15. Anwandter A, Bohmann S, et al. Dimensional changes of the post extraction alveolar ridge, preserved with Leukocyte- and Platelet Rich Fibrin: A clinical pilot study. J Dent 2016;52:23-29. DOI: 10.1016/ j.jdent.2016.06.005.

16. Castro AB, Meschi N, et al. Regenerative potential of leucocyte- and platelet-rich fibrin. Part A: intra-bony defects, furcation defects and periodontal plastic surgery. A systematic review and meta-analysis. J Clin Periodontol 2017;44(1):67-82. DOI: 10.1111/jcpe.12643.

17. Varghese MP, Manuel $S$, et al. Potential for Osseous Regeneration of Platelet-Rich Fibrin-A Comparative Study in Mandibular Third Molar Impaction Sockets. J Oral Maxillofac Surg 2017;75(7):1322-1329. DOI: 10.1016/j.joms.2017.01.035.

18. Daugela P, Grimuta V, et al. Influence of leukocyte- and plateletrich fibrin (L-PRF) on the outcomes of impacted mandibular third molar removal surgery: a split-mouth randomized clinical trial. Quintessence Int 2018;49(5):377-388. DOI: 10.3290/j.qi.a40113.

19. Zhang $Y$, Tangl S, et al. Effects of Choukroun's platelet-rich fibrin on bone regeneration in combination with deproteinized bovine bone mineral in maxillary sinus augmentation: a histological and histomorphometric study. J Craniomaxillofac Surg 2012;40(4): 321-328. DOI: 10.1016/j.jcms.2011.04.020.

20. Ozgul O, Senses F, et al. Efficacy of platelet rich fibrin in the reduction of the pain and swelling after impacted third molar surgery: randomized multicenter split-mouth clinical trial. Head Face Med 2015;11:37. DOI: 10.1186/s13005-015-0094-5.

21. Al-Hamed FS, Tawfik MA, et al. Efficacy of Platelet-Rich Fibrin After Mandibular Third Molar Extraction: A Systematic Review and MetaAnalysis. J Oral Maxillofac Surg 2017;75(6):1124-1135. DOI: 10.1016/ j.joms.2017.01.022.

22. Gulsen U, Senturk MF. Effect of platelet rich fibrin on edema and pain following third molar surgery: a split mouth control study. BMC Oral Health 2017;17(1):79. DOI: 10.1186/s12903-017-0371-8.

23. Pradeep AR, Rao NS, et al. Comparative evaluation of autologous platelet-rich fibrin and platelet-rich plasma in the treatment of 3-wall intrabony defects in chronic periodontitis: a randomized controlled clinical trial. J Periodontol 2012;83(12):1499-1507. DOI: 10.1902/ jop.2012.110705.

24. Kumar N, Prasad K, et al. Evaluation of treatment outcome after impacted mandibular third molar surgery with the use of autologous platelet-rich fibrin: a randomized controlled clinical study. J Oral Maxillofac Surg 2015;73:1042-1049. DOI: 10.1016/j.joms.2014.11.013.

25. Gandevivala A, Sangle A, et al. Autologous Platelet-rich Plasma after Third Molar Surgery. Ann Maxillofac Surg 2017;7(2):245-259. DOI: 10.4103/ams.ams_108_16.

26. Sammartino G, Tia M, et al. Use of autologous platelet-rich plasma (PRP) in periodontal defect treatment after extraction of impacted mandibular third molars. J Oral Maxillofac Surg 2005;63(6):766-770. DOI: 10.1016/j.joms.2005.02.010.

27. Sammartino G, Tia M, et al. Platelet-rich plasma and resorbable membrane for prevention of periodontal defects after deeply impacted lower third molar extraction. J Oral Maxillofac Surg 2009;67(11):2369-2373. DOI: 10.1016/j.joms.2009.04.093.

28. Padma R, Shilpa A. A split mouth randomized controlled study to evaluate the adjunctive effect of platelet-rich fibrin to coronally advanced flap in Miller's class-I and II recession defects. J Indian Soc Periodontol 2013;17(5):631-636. DOI: 10.4103/0972-124X.119281.

29. Eren G, Atilla G. Platelet-rich fibrin in the treatment of localized gingival recessions: a split-mouth randomized clinical trial. Clin Oral Investig 2014;18(8):1941-1948. DOI: 10.1007/s00784-013-1170-5.

30. Keceli HG, Kamak G, et al. The Adjunctive Effect of Platelet-Rich Fibrin to Connective Tissue Graft in the Treatment of Buccal Recession Defects: Results of a Randomized, Parallel-Group Controlled Trial. J Periodontol 2015;86(11):1221-1230. DOI: 10.1902/jop.2015.150015.

31. Jankovic $S$, Aleksic $Z$, et al. The coronally advanced flap in combination with platelet-rich fibrin (PRF) and enamel matrix derivative in the 
treatment of gingival recession: a comparative study. Eur J Esthet Dent 2010;5(3):260-273.

32. Gupta S, Banthia R, et al. Clinical evaluation and comparison of the efficacy of coronally advanced flap alone and in combination with platelet rich fibrin membrane in the treatment of Miller Class I and II gingival recessions. Contemp Clin Dent 2015;6(2):153-160. DOI: 10.4103/0976-237X.156034.

33. Moraschini V, Barboza Edos S. Use of Platelet-Rich Fibrin Membrane in the Treatment of Gingival Recession: A Systematic Review and Meta-Analysis. J Periodontol 2016;87(3):281-290. DOI: 10.1902/ jop.2015.150420.
34. Bilginaylar K, Uyanik LO. Evaluation of the effects of platelet-rich fibrin and piezosurgery on outcomes after removal of impacted mandibular third molars. Br J Oral Maxillofac Surg 2016;54(6):629-633. DOI: 10.1016/j.bjoms.2016.03.016.

35. Singh A, Kohli M, et al. Platelet rich fibrin: a novel approach for osseous regeneration. J Maxillofac Oral Surg 2012;11(4):430-434. DOI: 10.1007/ s12663-012-0351-0.

36. Asutay F, Yolcu Ü, et al. An evaluation of effects of platelet-richfibrin on postoperative morbidities after lower third molar surgery. Nigerian journal of clinical practice 2017;20:1531-1536. DOI: 10.4103/1119-3077.181400. 